\title{
EFFICIENT GARBAGE COLLECTION USING WSN
}

\author{
Chaitanya More ${ }^{1}$, Darshan Mestry ${ }^{2}$, Parag Kedia ${ }^{3}$, Reshma More ${ }^{4}$ \\ ${ }^{1}$ Computer Engineering (B.E.), P.I.C.T, Pune, Maharashtra, India \\ ${ }^{2}$ Computer Engineering (B.E.), P.I.C.T, Pune, Maharashtra, India \\ ${ }^{3}$ Computer Engineering (B.E.), P.I.C.T, Pune, Maharashtra, India \\ ${ }^{4}$ Computer Engineering (B.E.), P.I.C.T, Pune, Maharashtra, India
}

\begin{abstract}
This project aims at developing a Waste Management Sensor which would cater to the needs of the people of the society. A wireless sensor can be deployed in dumpsters and we can monitor the situation via a graphical interface. A dashboard holding information about all dumpsters, their capacity can be accordingly used for smart collection plans and monitoring further. For collecting information about the waste from dumpsters ultrasonic sensors will be used, which will sense the current capacity the dumpster and send the related information to cloud. From cloud the information will be transferred to the android application and website. Optimized schedule and route for disposing the waste in to dumpsters will be generated accordingly.
\end{abstract}

Key Words-Wireless Sensor Network, Cloud computing, Internet of things, Computer Networking $* * *$

\section{INTRODUCTION}

Solid waste management is a big challenge in urban areas for most of the countries throughout the world. An efficient waste management is a pre requisition for maintain a safe and green environment as there are increasing all kinds of waste disposal. There are many technologies are used for waste collection as well as for well managed recycling. The Information gathering is big and cumbersome. The concurrent effects of a fast national growth rate, of a large and dense residential area and a pressing demand for urban environmental protection create a challenging framework for waste management. The complexity of context and procedures is indeed a primary concern of local municipal authorities due to problems related to the collection, transportation and processing of residential solid waste

This project aims at developing a Waste Management Sensor which would reduce the travelling time and cost of garbage collection system by $50 \%$. Travelling cost and time will get reduced as information about dumpsters will be available on web and mobile application which will help the dumping schedule to be optimized.

\section{IMPLEMENTATION METHODOLOGY:}

The improved Garbage bins will contain Arduino kit with power supply, Ultrasonic sensor on the top of garbage bin. The working will be to capture the certain level of garbage filled inside the bin. The sensors will detect the level and it will pass the information to the Base Station of the area manager by sending information about the details of Trash, its location. On receiving the information the area manager can immediately deploy a pickup vehicle (GPS enabled) to clean the garbage bin. The bin gets cleaned a message of cleaning of that particular bin will be sent to the area manager. Basically, this will keep track of everything and it will help in providing better solution to keep the city clean, save the time of workers, save fuel of pickup vehicles, etc.

\section{MOTIVATION OF THE PROJECT}

Waste management is one of the biggest issues in urban development. As population goes increasing, the waste also gets increased to great ex-tent. So managing waste using a trasditional way is no longer efficient. We can place sensors in dumpsters and monitor the situation via a graphical interface. A dashboard will hold information about all dumpsters, their capacity, current holding situation and remaining storage. Also routes of those dumpsters can be access via web application. So that the waste management can be done efficiently. The sensors can also include motion detectors and thermometers, which will allow them to detect successful pickups as well as provide alerts about unusual events, like vandalism or trash res. They will be bolted to the inside of each dumpster. The data can be forwarded by sensors to the central point and the can be stored on server. Then it can be accessed by mobile application or a web application. After this digitization process, the issue of waste management can be reduced to some extent.

\section{ARCHITECTURE DIAGRAM:}

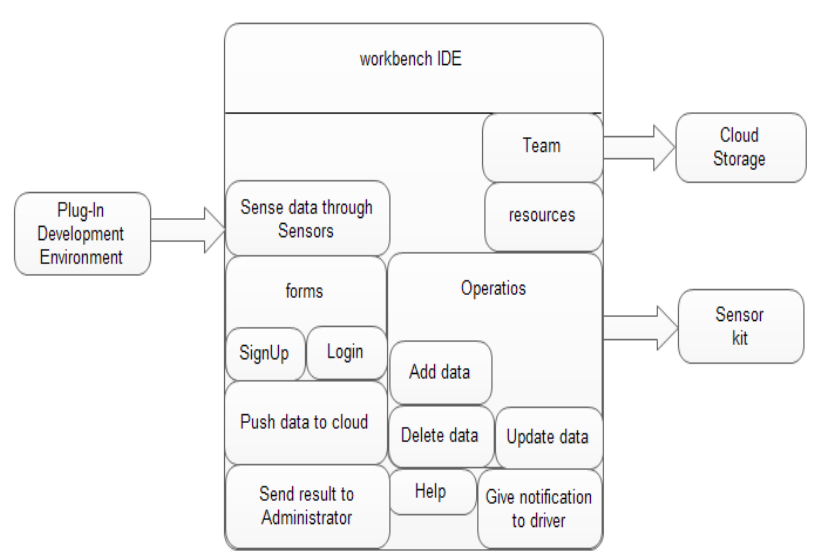




\section{HARDWARE DESCRIPTION}

\subsection{Power Supply:}

For power supply we will use lithium battery or any other alternative source can also be used as per feasibility.

\subsection{Arduino mega2560}

The Mega 2560 is a microcontroller board based on the ATmega2560. It has 54 digital input/output pins (of which 15 can be used as PWM outputs), 16 analog inputs, 4 UARTs (hardware serial ports), a $16 \mathrm{MHz}$ crystal oscillator, a USB connection, a power jack, an ICSP header, and a reset button. It contains everything needed to support the microcontroller; simply connect it to a computer with a USB cable or power it with an AC-to-DC adapter or battery to get started.

\subsection{HC-SRO4 Ultrasonic sensor}

The HC-SR04 ultrasonic sensor uses sonar to determine distance to an object like bats or dolphins do. It offers excellent non-contact range detection with high accuracy and stable readings in an easy-to-use package. From $2 \mathrm{~cm}$ to $400 \mathrm{~cm}$ or 1 " to 13 feet. It operation is not affected by sunlight or black material like Sharp rangefinders are (although acoustically soft materials like cloth can be difficult to detect). It comes complete with ultrasonic transmitter and receiver module.

\subsection{Wi-Fi module ESP8266}

The ESP8266 is a low cost Serial-to-Wi-Fi module that interfaces nicely to any microcontroller. The ESP8266 has a full TCP/UDP stack support. It can also be easily configured as a web server. The module accepts commands via a simple serial interface. It then responds back with the operation's outcome. Also, once the device is connected and is set to accept connections, it will send unsolicited messages whenever a new connection or a new request is issued.

\section{STATE DIAGRAM:}

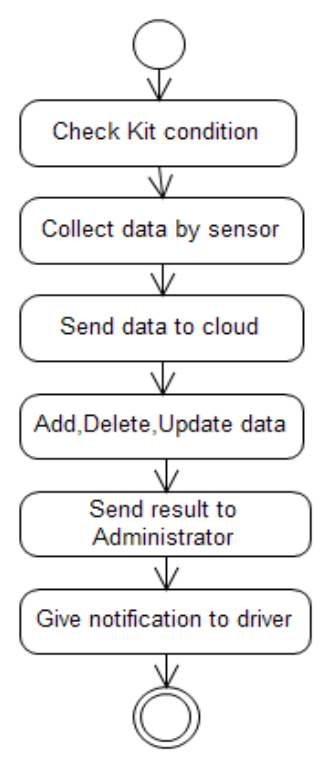

\section{CONCLUSION:}

Thus the project stands out from the rest in many different aspects providing a cost-efficient and timely Pickups of Trash bins. A Small battery powered wireless sensors monitor each containers filled level in real time. Also the sensors are remotely attached and hidden away out of sight inside the container. It helps in less scattering of waste and a better hygiene in order to Solve many problems in the society.

\section{REFERENCES}

[1] Smart Garbage collection system in residential area, Gaikwad Prajakta, Jadhav Kalyani, Machale Snehal, Electronics and Telecommunication, B.V.C.O.E.W, Maharashtra, India, IJRET: International Journal of Research in Engineering and Technology.

[2] Efficient Garbage Disposal Management in Metropolitan Cities Using VANETs

Narendra Kumar G., Chandrika Swamy, and K. N. Nagadarshini.

[3] International Journal of Computer Science \& Engineering Survey (IJCSES) Vol.3, Energy Saving in Wireless Sensor Networks, Zahra Rezaei,Shima Mobininejad,Department of Computer Engineering Islamic Azad University, Arak Branch, Arak, Iran.

[4] Internet of Things for Smart Cities Andrea Zanella, Senior Member , IEEE, Nicola Bui, Angelo Castellani, Lorenzo Vangelista, Senior Member IEEE, and Michele Zorzi, Fellow, IEEE.

[5] Automatic Scaling of Internet Applications for Cloud Computing Services Zhen Xiao, Senior Member, IEEE, Qi Chen, and Haipeng Luo.

\section{BIOGRAPHIES}

Chaitanya More,

Computer Engineering (B.E.),

P.I.C.T Pune,

Maharashtra,

India.

Darshan Mestry,

Computer Engineering (B.E.),

P.I.C.T Pune,

Maharashtra,

India.

Parag Kedia,

Computer Engineering (B.E.),

P.I.C.T Pune,

Maharashtra,

India.

Reshma More,

Computer Engineering (B.E.),

P.I.C.T Pune,

Maharashtra,

India. 